\title{
ВЫБОР ОПТИМАЛЬНОГО ПОДХОДА К ФОРМИРОВАНИЮ КРЕДИТНОГО ПОРТФЕЛЯ РОССИЙСКОГО БАНКА
}

\section{CHOOSING THE OPTIMAL APPROACH TO THE FORMATION OF THE RUSSIAN BANK'S LOAN PORTFOLIO}

\section{Golovanov}

Summary. For a modern Bank, the formation of a credit portfolio is a fundamental activity: the credit portfolio is both the largest source of income and the main source of risk. Therefore, effective management of a commercial Bank's loan portfolio is based on choosing the optimal approach to forming such a portfolio. Until recently few Russian banks have used the modern concepts of credit portfolio management. The problems associated with the formation of an optimal loan portfolio are still relevant today. Incorrect formation of the loan portfolio can lead to serious legal or financial problems. The author of the article considers the optimal approach to the formation of a credit portfolio based on credit risk management both from the point of view of managing individual segments of the credit portfolio and the entire portfolio as a whole. The developed approach will allow expanding traditional risk management methods by using more tools for analyzing and controlling the risk of the loan portfolio, as well as reducing the Bank's losses associated with lending.

Keywords: credit portfolio, credit portfolio risks, credit portfolio management, credit policy, commercial banks, risk profile, credit portfolio segmentation, credit portfolio formation.

\author{
Голованов Владислав Сергеевич \\ Аспирант, Финансовый университет при \\ Правительстве Российской Федерации, г. Москва \\ golovanovvs@yandex.ru
}

Аннотация. Для современного банка формирование кредитного портфеля — это основополагающее направление деятельности: кредитный портфель одновременно является и крупнейшим источником дохода, и главным источником риска. Поэтому в основе эффективного управления кредитным портфелем коммерческого банка лежит выбор оптимального подхода к его формированию. До недавнего времени мало кто из российских банков использовал современные концепции управления кредитным портфелем. Проблемы же, связанные с формированием оптимального кредитного портфеля, актуальны и сегодня. Неправильное формирование кредитного портфеля может привести к серьезным проблемам юридического или финансового характера.

Автором статьи рассматривается оптимальный подход к формированию кредитного портфеля, основанный на управлении кредитным риском как с точки зрения управления отдельными сегментами кредитного портфеля, так и всего портфеля в целом. Разработанный подход позволит расширить традиционные методы управления рисками за счет большего количества инструментов для анализа и контроля риска кредитного портфеля, а также уменьшить убытки банка, связанные с кредитованием.

Ключевые слова: кредитный портфель, риски кредитного портфеля, управление кредитным портфелем, кредитная политика, коммерческие банки, профиль риска, сегментация кредитного портфеля, формирование кредитного портфеля.

к формированию оптимального кредитного портфеля сводятся к построению математических моделей, использующих в качестве производных данных различные показатели. Так, одним из первых фундаментальных трудов, описывающих формирование оптимальной структуры портфеля активов, традиционно считают портфельную теорию Г. Марковица [4, с. 38], в основе которой лежит подход к оптимальному выбору активов исходя из требуемого соотношения доходность/риск. Из российских исследователей тематике портфельной теории посвящены работы Е.И. Аверкина [2, с. 15], Н.Б. Баевой [1, с. 17], Р.Т. Балакина, П. В. Галдецкого [3, с. 20], О.И. Лаврушина [6, с. 78; 7, с. 20-21], Д.А. Трифонова [8, с. 163]. Предложенные вышеназванными исследователями подходы к формированию оптимального кредитного портфеля коммерческого банка представлены в виде задач математического программирования с жесткими ограничениями, учитывающими отдельные показатели 
состояния современных банковских систем, либо в виде вариантной модели, в которой учитываются интересы заемщика.

По мнению автора статьи, процесс формирования кредитного портфеля невозможно отделить от процесса управления таким портфелем. Поэтому оптимальным подходом к формированию кредитного портфеля будет подход, в основе которого лежит процесс управления кредитным портфелем и его рисками, а не математические уравнения оптимизации.

В финансовой литературе управление в широком смысле определяется как процесс целенаправленного, систематического и непрерывного воздействия управляющей подсистемы на управляемую с помощью общих функций управления, образующих замкнутый и бесконечно повторяющийся управленческий цикл $[5,9]$.

Р.Т.Балакина и П.В. Галдецкий определяют процесс управления кредитным портфелем как последовательность действий, ведущую к определенной цели - формированию кредитного портфеля. При этом, по мнению авторов, в последовательность действий включаются взаимосвязанные процедуры целеполагания, планирования, прогнозирования, анализа и оценки ситуации, организации, выявления проблем, координации, учета и контроля, принятия управленческих решений, которые осуществляют субъекты управления.

По мнению автора статьи, само по себе управление портфелем означает определение состава портфеля (установление кредитных лимитов и выбор конкретных кредитных линий) и присущих ему рисков (возможные потери). При управлении кредитным портфелем определяется не только количество продуктов портфеле, но и их отраслевая и географическая концентрация, средний риск, рейтинги и другие совокупные характеристики. При этом акцент на управлении кредитным риском портфеля должен быть сделан как на отдельных сегментах портфеля, так и на всем портфеле в целом. Такой подход позволит диверсифицировать риски портфеля при его формировании.

Диверсификация рисков является основным принципом управления портфелем. Концентрация кредитного риска происходит в пределах кредитного портфеля, когда в целом несвязанные кредиты объединяются при формировании портфеля какой-то общей характеристикой. В дальнейшем, если такая общая характеристика становится общим источником проблем для займов в условиях концентрации, займы могут представлять значительный риск для доходов и капитала. Управление кредитным портфелем включает в себя управление любой концентрацией риска. Сегментируя портфель на пулы кредитов с аналогичными характеристиками, можно оценивать их в свете целей портфеля и допустимых рисков банка и, при необходимости, разрабатывать стратегии снижения, диверсификации или иного смягчения связанных с ними рисков.

Для выбора наиболее оптимального подхода к формированию портфеля осуществляется идентификация рисков. Эффективная идентификация рисков начинается с оценки отдельных кредитов. Оценка риска каждого кредита при своевременной оценке кредитоспособности имеет основополагающее значение для управления кредитным портфелем. Одни банки применяют рейтинги рисков к отношениям, другие предпочитают оценивать каждый объект, третьи оценивают как отношения, так и объекты. Любой из подходов к оценке приемлем для целей идентификации риска с целью дальнейшего формирования портфеля. Вместе с тем, рейтинги риска также должны применяться и к внебалансовым рискам, таким, как аккредитивы и необеспеченные обязательства, которые банк обязан финансировать, если не произойдет дефолта. Эти оценки позволяют оперативно выявлять изменения в качестве портфеля, позволяя при этом своевременно модифицировать портфельные стратегии и активизировать контроль за более слабыми кредитами. После оценки риска по каждому кредиту следует пересмотреть рейтинги отдельных кредитов и проанализировать их в разрезе сегмента портфеля и всего портфеля в целом. Анализ должен обеспечивать последовательное применение рейтингов и учитывать тенденции, данные об изменении и средневзвешенные оценки рисков. Рейтинги рисков, используемые в сочетании с другой информацией (например, уровни исключений, просроченные задолженности и рост кредитов), могут дать информацию о качестве активов и уровне кредитного риска.

Сегментирование портфеля и диверсификация рисков требуют комплексных систем управленческой информации. База данных должна включать в себя как балансовые, так и внебалансовые кредитные риски. Если банк не располагает адекватными данными по каждому кредиту или не располагает системой, позволяющей выбрать данные для анализа, то возможности по управлению кредитным портфелем оказываются под угрозой.

Для многих российских банков «сегментация портфеля» обычно означает разделение кредитного портфеля на широкие категории по видам кредитов, например, на кредиты юридических или физических лиц. По общему правилу сегментация кредитного портфеля по видам кредитов (или как их принято называть в банковской среде кредитным линиям) - это исходная точка при формировании портфеля. Однако преимущества сегментации портфеля можно оценить только в том случае, 
если банк способен формировать кредитные пулы, используя более широкий диапазон характеристик риска.

Определяющими характеристиками сегментов могут быть: отрасль заемщика, наличие залогового обеспечения, рейтинг риска, наличие государственных и муниципальных контрактов, длительность работы на конкретном товарном рынке, кредиты с общей целью или источником погашения и пр.

Вместе с тем, даже при формировании кредитных портфелей пулами, с широким диапазоном характеристик риска для идентификации концентрации риска это только половина работы. Понимание динамики концентрации и того, как она будет вести себя в различных экономических сценариях - это вторая половина. Поскольку информация о конкретной концентрации риска уточняема, ее влияние на профиль риска портфеля можно оценить. Например, банк с концентрацией заемщиков и кредитов в нефтяной отрасли должен иметь возможность отслеживать развитие событий в этой отрасли, отслеживать эффективность сегмента портфеля и соотносить изменения в этом сегменте с общим портфелем. При этом, банки не должны брать на себя риски в отраслях или продуктах, в которых они не могут разобраться.

В идеале общий состав кредитного портфеля и уровень риска в различных пулах должны соответствовать целям и руководящим принципам, установленным кредитной политикой банка. Однако, нередко один или несколько пулов вызывают проблемы либо из-за рисков, связанных с кредитами, либо из-за большого объема кредитов с аналогичными характеристиками. Для исключения подобных ситуаций каждый пул должен оцениваться индивидуально - то есть как отдельный пул риска - и как часть целого - то есть по тому, как он вписывается в портфель и поддерживает цели кредитного портфеля. Цель банка при формировании портфеля состоит в достижении желаемого баланса риска и доходности для портфеля в целом. Целенаправленное воздействие на основные показатели качества кредитного портфеля при его формировании путем выделения кредитных пулов портфеля за счет широкого диапазона характеристик риска, позволит усилить роль банков без существенной потери качества кредитования.

Небольшие банки могут, например, накапливать концентрацию риска из-за их более ограниченного географического рынка и характера местной экономики. Более крупные банки могут развивать концентрацию рисков путем слияний или для получения рычагов воздействия или наращивания отраслевого опыта. В любом случае банк должен решить, представляет ли тот или иной пул кредитов нежелательную концентрацию риска, которую следует уменьшить, или нет. Заемщики при концентрации портфеля могут иметь схожие финансовые характеристики, например, источники капитала, источники погашения и структуру баланса. При формировании портфеля определяются общие характеристики, влияющие на кредитный риск. Сосредоточение усилий на этих характеристиках одновременно упрощает и усиливает надзор за рисками в рамках кредитного пула, а стресс-тестирование с использованием общих финансовых показателей позволит определить, какие пулы наиболее подвержены кредитному риску и требуют повышенного внимания.

Так, например, когда значительные отдельные кредиты или сегменты портфеля особенно чувствительны к риску изменения процентной ставки, их следует периодически подвергать стресс-тестированию. Банки часто перекладывают процентный риск на своих заемщиков, структурируя кредиты с переменными процентными ставками [10]. Заемщики с предельной платежеспособностью могут столкнуться с финансовыми трудностями, если процентные ставки по этим кредитам возрастут. В рамках процесса управления рисками банки должны выявлять заемщиков, чьи кредиты обладают повышенной чувствительностью к изменениям процентных ставок, и разрабатывать стратегии снижения риска. Один из методов заключается в том, чтобы требовать от уязвимых заемщиков покупать специальную защиту процентной ставки (например, за счет дополнительной услуги по страхованию), или иным образом хеджировать риск.

Резюмируя вышесказанное, можно сделать вывод о том, что существует множество возможностей сегментировать кредитный портфель, которые можно использовать для управления им и контроля риска. Однако еще одним наиболее распространенным методом сегментации кредитного портфеля является установка пределов воздействия или «потолков» концентрации риска портфеля. Диверсификация рисков такого портфеля от пределов воздействия может быть достигнута за счет уменьшения определенных рисков или увеличения базы заемщика. Сокращение рисков начинается с переоценки потребностей отдельных заемщиков и требует значительной дисциплины. Тем не менее, это может быть полезным инструментом для диверсификации рисков по большой клиентской базе. При таком подходе банк может всегда изменить распределение своих активов, увеличив географическую диверсификацию заемщиков; изменив ассортимент банковских продуктов (например, путем сокращения коммерческого кредитования и увеличения потребительского кредитования) или изменив профиль риска целевого рынка банка (например, переход от клиентов неинвестицион- 
ного уровня к хорошо капитализированным клиентам инвестиционного уровня).

Подводя итог настоящему исследованию, необходимо отметить, что в современных условиях наиболее оптимальным подходом к формированию кредитного портфеля российского банка является подход, в основе которого лежит процесс управления как отдельными сегментами кредитного портфеля, так и всего портфеля в целом. Такой подход позволяет расширить традиционные методы управления рисками за счет большего количества инструментов для анализа и контроля риска кредитного портфеля, а также уменьшить убытки банка, связанные с кредитованием.

\section{ЛИТЕРАТУРА}

1. Баева Н. Б. Основы теории систем и вычислительные схемы системного анализа: учебник для вузов / Н. Б. Баева, Д. В. Ворогушина, Е. В. Куркин.- - Воронеж: Изд-во ВГУ, 2009. - 37 с.

2. Баева Н.Б., Аверкин Е. И. Процесс формирования кредитного портфеля коммерческого банка с применением вариантной модели // Вестник Воронежского государственного университета Серия: Системный анализ и информационные технологии. — 2019. — № 1. Январь — Март.

3. Балакина Р.Т., Галдецкий П. В. Теоретические аспекты управления кредитным портфелем банка // Вестник Омского университета.— 2014.— № 1.— C. 20.

4. Касимов Ю. Ф. Основы теории оптимального портфеля ценных бумаг / Ю. Ф. Касимов.— М.: Информ. — изд. дом «Филинъ», 1998.

5. Ковалев В. В. Финансовый менеджмент: теория и практика.—М.: Проспект, 2006. - 1016 с.

6. Лаврушин 0.И., Мамонтова И. Д., Валенцова Н. И. Банковское дело. — М., 2010. — С. 78.

7. Лаврушин 0.И. Банковские риски.-М., 2009.- С. 20-21.

8. Трифонов Д. А. Эволюция портфельных подходов в банковском менеджменте // Финансы и кредит.— 2011. — № 9 (411).

9. Пашков А. И. Оценка качества кредитного портфеля // Бухгалтерия и банки. — 1996. — № 3.

10. Чертопруд С. Битва за кредиты // Банковское обозрение. - 2015.—№ 2.

(с Голованов Владислав Сергеевич (golovanovvs@yandex.ru ).

Журнал «Современная наука: актуальные проблемы теории и практики»

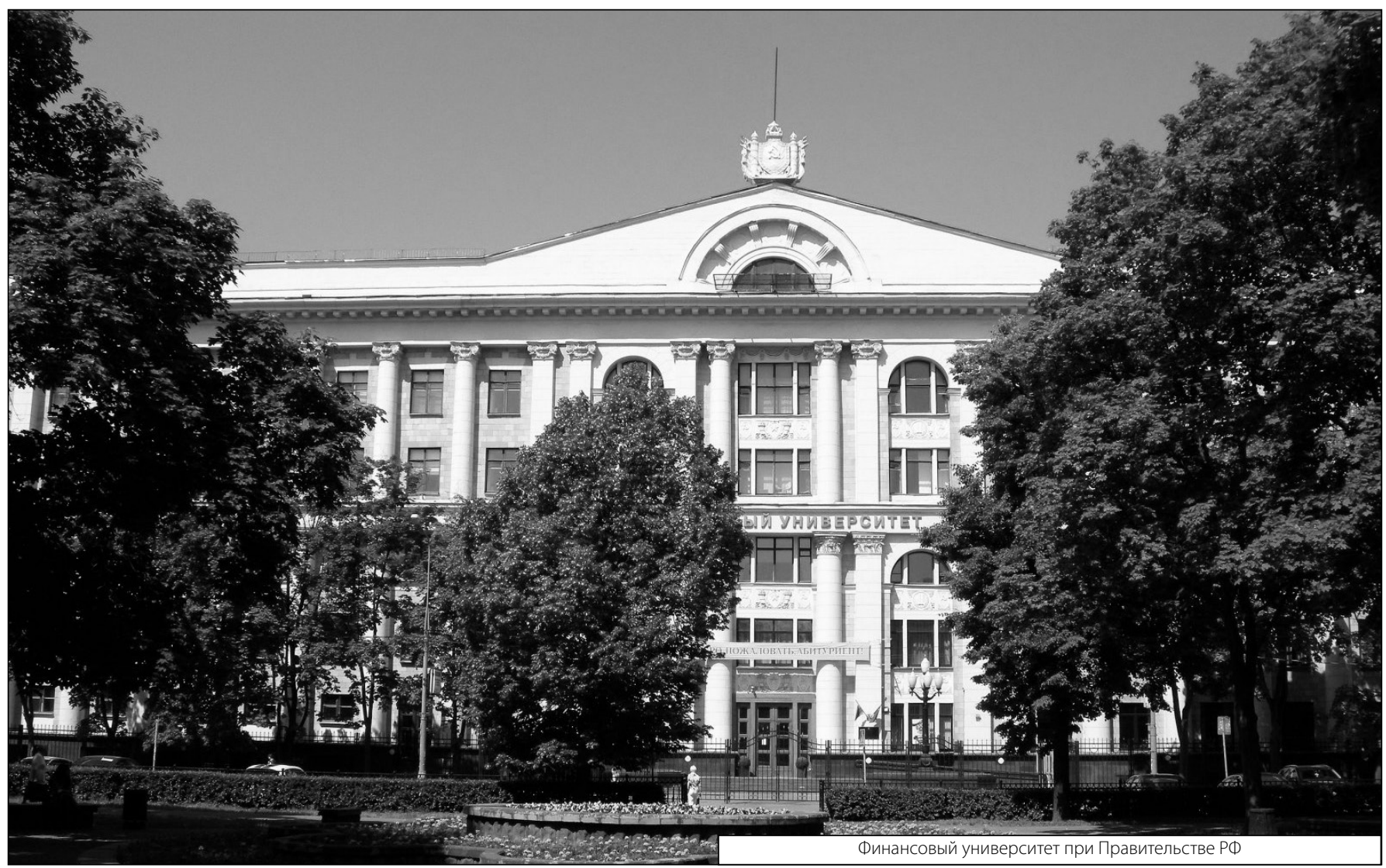

